\title{
The Impact of Staging Olympic Games on Real Estate Price in Beijing
}

\author{
Tang Xuebing (Corresponding author) \\ School of Economics and Management \\ Huazhong Normal University \\ Wuhan, China \\ E-mail: xuebingt@126.com \\ Yao Yongling \\ Regional and Urban Economic Institution \\ Renmin University of China \\ Beijing, China \\ E-mail: yaoyongling@gmail.com
}

Received: January 6, 2012

Accepted: February 11, 2012 Published: March 15, 2012

doi:10.5430/rwe.v3n1p45

URL: http://dx.doi.org/10.5430/rwe.v3n1p45

The research was supported by 2010 Major Project Development Scheme in Central University Basic Research Fund in Huazhong Normal University "Regional economic policy in China: combinational goals, realizing path and dynamic evaluation" and 2009 Dangui Scheme in Huazhong Normal University "the implementation mechanism of the equalization of basic public services in Hubei" (09DG019).

\begin{abstract}
The price of the real estate in many cities of China has been rising up rapidly since a couple of years ago. Particularly, the increasing period is coinciding with the period of economic rising in Beijing. Therefore, many people thank that the higher price is mostly made by holding Olympic Game in 2008. In order to separate Olympic factor and non-Olympic factors, which were supposed to impact the price of real estate in Beijing, Differences-in-Differences (DD) method will be adopted in this paper. With this method, Olympic period \& non-Olympic period, Olympic cities \& non-Olympic cities will be defined. The result could be denoted to assess the impact of holding Olympic Games on real estate price in Beijing. Meanwhile, surveying data person by person and economic cycle analysis will be used to support the result. The conclusion is that Olympic factor enlarged only the extent of increasing and decreasing in the economic cycle other than changing the tendency of the price cycle of the real estate.
\end{abstract}

Keywords: Olympic Games, Price of the Real Estate, Macroeconomic Cycle

The price of real estate in large cities of China has been the rising period since 2000 . The one in Beijing has being a great extent since 2004. Staging Olympic Games in 2008 is just during this period. How much have the preparing activities impacted on the price of real estate in Beijing has become one of the hot topics.

In order to discover the riddle, appropriate way to divide Olympic Game factor from non-Olympic factors is needed. This is a technical approach to define "impact or not", however, there have not been accurate approach to separate "impact or not" in the world. The way most common used is stage-comparison-approach, namely the comparison the actual observed value about the criteria within the event and the changing tendency of the value without the event. The distance between them is taken as the impact of the event on the criteria. Owning to lot of uncertain factors has been appeared during staging Olympic Games, this method is too general to be used judging the "impact or not" exactly. Therefore, the key technique is to find appropriate reference period or objects.

The Difference-in-Difference (DD) makes use of the dual different results of the cross unit and time series which are brought by extra event to compare the difference between the objects with event (treatment group) and those without event (reference group) to judge the impact degree of the event. DD method will be adopted in this paper by taking Beijing with 
Olympic Games as the treatment group and other non- Olympic Games host cities as the reference group, to seek for non-Olympic Games reference objects. At the same time, time series will be also used to compare the succession of Olympic impact, the result can be made a brief forecast about real estate price in Beijing during post-Games period. No doubt, this method is a progress in separating "impact or not" by analyzing data from both temporal and special dimensions.

\section{The Changes of Real Estate Price in Beijing and Former Hosting Cities}

There were two periods to describe the price-changing period of real estate in Beijing since 1998 when there was real estate market in China. The first stage is 1998-2001, which can be taken as non-Olympic time with the growth rate of price index $0.45 \%$ yearly. The second stage is $2002-2006$, which can be taken as Olympic time with staging Olympic Games, growth rate of real estate price index is $4 \%$ yearly. During the second period, both the housing price and Gross Domestic Product (GDP) has been accelerating since 2004. The price index of real estate is $106.9 \%$ in 2005 and $108.8 \%$ in $2006,3.2 \%$ and $1.9 \%$ higher than those of last year. And the selling price index of commodity was $107.1 \%$ in 2005 and $109.6 \%$ in 2006, 2.8\% and 2.4\% more than those of last year. Meanwhile, the national GDP has been increasing by $10 \%$ yearly since 2003 , leading to the rapid growth of real estate price in many cities at that time. The price of commercial houses was climbing sharply especially in Shanghai, Guangzhou, Shenzhen, etc. The annual GDP growth in Beijing was $16.14 \%$ during 2002-2006, which would be the dynamic of high real estate price. Hence, real estate price is by reinforcing of integrative factors.

Real estate price grew by 19\% during the preparing 26th Olympic Games period in Atlanta while the growth rate of other cities all around in US is 13\% averagely. During 1993-1995, 33000 houses were sold annually in Atlanta, which performed the best one in US. Although the price of real estate kept rising after staging of Olympic Games, it was apparent lower growth rate than other northeastern or the west coast city in US. It is mainly because that the municipal government had spent 1 billions US\$ to reconstruct the basic infrastructure at that time in order to preparing the Games, which activated the local real estate's market, which was unusual in other megalopolises of US. It seems that Olympic Games indeed made great influence on Atlanta's real estate market. However the impact was coincided with other two factors: firstly, the price of real estate was lower than those of other American megalopolises; secondly, the period of 1992-2000 was the rising period of new economy in US which also the positive factor for influencing real estate price.

Since Sydney was selected as the host city for 2000 Olympic Games in 1993, the growth rate of real estate price o had been more than $10 \%$ yearly, even doubled in 2000, and continuously rising till 2003. But the price in Sydney has been decreasing since 2004. Therefore, it appears that staging Olympic Games affected real estate price in Sydney.

The price of the real estate in Athens, the 2004 Olympic Game host city, had increased by $75 \%$ during the seven years from 1995 to 2002. The growth rate of house price has surpassed $110 \%$ along two new subways, as well as some places around several main Olympic Games facilities in Athens. It appears that that Olympic Games had promoted house price of Athens indeed.

The above cases about fluctuation of real estate price give the proof that staging Olympic Games had impact on real estate price. Because urban population and the demand for houses in these cities were comparatively stable. When China is being the rapid progress of urbanization, sharp growth of urban population proposed the huge demand for housing, as well as, Beijing is being in the critical phase to international metropolis, any positive factor can increase real estate price higher. Therefore, it is necessary to define Olympic or non-Olympic factors which impact real estate price in Beijing.

\section{Methodology}

When DD method is used, an assumption is needed. It is that in this paper staging Olympic Games has mad difference of real estate price in Beijing not only between pre- and staging the Games, but also between host city and other non-host cities. Twice difference estimates will be taken with regression models when using this method. As a result, the estimated values can efficiently control the influence from temporal and spatial effects.

The spatial difference will be defined by the host city and other non-host cities. In order to make the research objects comparable, we choose the municipality and the vice-provincial level cities as samples. Due to Shanghai will stage the World Exhibition in 2010, which could increase real estate price, it is eliminated out of the samples. Therefore, the number of the sample cities is seventeen totally. Among them, four hosting cities (Beijing, Tianjin, Shenyang, Qingdao) will be taken as the treatment group and, other thirteen non-Olympic cities the reference group.

The temporal difference will be defined with the year 2001, when the staging opportunity was obtained by Beijing. The period before 2001 is denoted as non-Olympic period and the one after 2001 as the Olympic period.

The Econometric model is the followings: 
$y_{i t}=\partial+u_{i}+\beta O G_{i} *$ time $_{t}+\gamma O G_{i}+\delta$ time $_{t}+\phi X_{i t}+\varepsilon_{i t}$

where $y_{i t}$ is the selling price index of real estate at time $t$ in city $i, O G_{i}$ is the dual dummy variable to distinguish the treatment group and the reference group ( 1 represents the treatment city, namely the host city), time $e_{t}$ is the dummy variable to distinguish pre- and staging Olympic Games period ( 1 represents staging period), $X_{i t}$ is a kind of controlling variables including per-capita GDP, the population density of built-up zone and investment of real estate at time $t$ in city $\mathrm{i}$ (see the followings); $\varepsilon$ it is the error variable of regression. $\beta, \gamma, \delta, \varphi$ is estimate parameters, $\beta$ may explain the difference between treatment group and reference group resulting from Olympic Games on $y_{i t}$, which is Olympic impact on the treatment city.

$\mathrm{a}+\mathrm{u}_{\mathrm{i}}$ is intercept (constant parameter), in which $u_{i}$ measures individual difference among samples. There are three situations: If $u_{i}$ is invariable value, the model is so-called fixed effect model; If $u_{i}$ is a random value, it is so-called random effect model; If $u_{i}$ doesn't change along with samples, it is so-called mixed regression model, in this case OLS regression can be used to do estimating directly. Therefore, doing regression analysis OLS can be used firstly to do estimating, and then the estimating values will be tested with regression values gained by the fixed panel calculation. When there is great difference between the two estimated values, Hausman specification test should be used to judge consistency of the results, or estimated value can be used directly without Hausman specification test.

\section{Indicators and Data}

As DD method is specially estimating influence from exterior factors. But the price of urban real estate is mostly determined by the interior economic factors and the demand of housing. Per capita GDP, urban population density of the built-up zone and real estate investment will be selected as controlling variables. These variables are the interior economic factors affecting the price of urban real estate. In order to interpret price changing of individual urban real estate with interior and exterior factors altogether, these factors should be applied.

Per capita GDP: Growth of Per capita GDP symbolizes the enhancement of people's living standard, which comes into being potential purchasing power of commercial house and leads to real estate price rise. Therefore, it can be concluded that the impact of per capita GDP on price index of real estate is positive. Owing to difference of economic developmental and consuming capability among cities, the value of per capita GDP will be converted by GDP implicit index; then logarithm form will be taken in order to enable per capita GDP to be compare in each city.

Urban population density of the built-up zone: The main demand sector of real estate is inhabitant; hence the quantity, quality and makeup of urban population make tremendous influence on real estate price. Urban built-up zone is the main supply place of commercial buildings; so that, house price is mainly decided by both the demand and supply from urban built-up zone. Specially, with increase of urban population density in built-up zone, demand pressure of real estate promote real estate price rise. Therefore, it can be concluded that the impact of urban population density in the built-up zone on price index of real estate is positive. Logarithm form will also be taken when doing estimating.

Investment in real estate: Investment in real estate increase certainly supply of commercial buildings, which will decline house price. However, the influence of real estate investment on house price is very complicated; being simple positive or negative relation is by no means. They influence mutually each other. On one hand, the acceleration of real estate investment will raise supply of commercial houses to relieve the pressure of price rising. On the other hand, the increase of real estate investment suggests that people should be optimistic to real estate market, the real estate dealer and investing consumer will increase real estate price. Therefore, it is difficult to give judgment about that real estate investment affecting on real estate price is positive or negative. The value of real estate investment will be converted by GDP implicit index, then logarithm form will also be taken.

Dummy variables: There are several dummy variables in this paper will be denoted as the followings:

1. Space, when sample is host city, space equals to 1 ,otherwise 0 .

2. Time, if the year is before 2002, time value is 0 , and 1 after 2002 (2002 included).

3. The dummy variable of both host cities and the period after 2002 will be denoted 1 , otherwise 0 . On the other hand, annual dummy variables to estimating Olympic impact changing with time will also be selected from 2001 to 2005 .

All the data will be obtained from Chinese City Statistical Yearbooks (1998-2006) in this paper.

\section{Regression Analysis}

In order to differentiate accurately the influence of Olympic Games from non-Olympic Games factors, regressions have to be analyzed twice according to above specification.

\subsection{Optimal Least Squares Regression (OLS)}


Firstly, the coefficients of the above equation will be estimated by OLS. When different independent variables are selected, the coefficients can be obtained with five times regressions with OLS (see Table 1 for the results).

$<$ Table 1 about here $>$

As OLS regression above, Column 1 is the first regression, without considering controlling variables. The result indicated that impact coefficient of staging Olympic Games on selling price index of house is 1.69 by comparing with Olympic event and non-Olympic event, which indicates that Olympic Games had approximately made impact on price rising of real estate by $1.69 \%$; but it is not significant at $90 \%$ confidence level. At the same time, impact coefficient of Olympic Games on selling price index of house is 3.74 during the period of preparing Olympic Games in different cities; the significance is at $99 \%$ confidence level, which shows that in the period of preparing Olympic Game, the impact is remarkable.

Column 2 shows the regression results when the period of preparing the Olympic Games was only tested excluding Olympic factor. The coefficient is 4.12, bigger than the first result, which further confirmed the coefficients in Column 1. It is clear that selling price increase of house in host cities is resulted from both macroeconomic cycle and Olympic factors together.

Column 3 shows the results with annual dummy variables in the years of 2001, 2002, 2003, 2004 and2005. It reveals that Olympic impact on selling price index of house is $1.02,-1.83,0.70,5.88$ and 3.02 respectively. It appears also that Olympic impact in the fourth year (2004) was more significant than other years and the increase of $5.87 \%$ about house selling price was resulted from Olympic factors. However, the impacts in other years were not significant. That gives the proof that Olympic impact on house price lagged for two or three years.

Column 4 shows regression results when the fourth year of preparing the Olympic Games was only tested excluding other years. The coefficient of intercept, Olympic impact and the one in the fourth year is 1.60, 3.83 and 5.27 respectively, and they are all significant at $99 \%$ confidence level. It indicates further that Olympic impact on house price lagged two or three years.

Column 5 shows the results when other controlling variables affecting on the house price such as per capita GDP, urban population density of built-up zone and real estate investment are introduced into the equation. It is identifiable that the regression coefficients are smaller than the one of the Olympic period (3.89), except for the one of intercept variable (5.78). Moreover, the regression result of Olympic period is significant at $99 \%$ confidence level and the ones of other independent variables are not significant at $90 \%$ confidence level. This confirms that the increasing price of real estate in host cities had not significant correlation with per capita GDP, urban population density of built-up zone and real estate investment. It indicates that urban real estate price is typical supply-driven rather than income-driven or demand-driven. Therefore, real estate price was decided by exterior factors other than market factors indeed.

Moreover, the results of independent variables about period of preparing and Olympic impact in column 1 and 5 are quite consistent, which provided support that the sample is approximately stochastic.

\subsection{Differences-In-Differences Regression}

Secondly, differences-in-differences regressions will be taken with above data by fixed-effect panel model. Based on the first difference estimation, the second difference estimation on temporal series can be made according to Olympics scenario or non-Olympics one by regression analyzing on different independent variables for six times (see Table 2).

\section{$<$ Table 2 about here $>$}

As shown in Table 2, each column gives meaning as the followings:

Column 1 is the results which show the influencing coefficients of intercept. It indicates the quite consistent results with those in table 1 . This is proved that $1.69 \%$ rise of house selling price in host cities has been resulted from Olympic factor, however, the impact was not significant.

Column 2 and 3 accounts further that Olympic impacts of the first three preparing years on real estate price were not significant, but the one of the fourth year was an adverse case. The difference of the two regression methods results is the coefficients in the fifth year. The coefficient by using differences-in-differences regressions is 3.13 with being significant at $95 \%$ confidence level. It demonstrates that the impact in the fifth preparing year is still significant; $3.12 \%$ of house selling price was resulted from Olympic factors. Therefore, the closer to stage Olympic Games is, more significant is the Olympic impact on house price.

Column 4 in Table 2 corresponds with Column 5 in Table 1 . The regression coefficients are 6.35,0.61 and 1.37 when three interior factors affecting the housing pricing were introduced respectively. They are the meaning like that: impact 
of urban population density of built-up zone on the house pricing is $0.6 \%$ or so, but not significant; impact of urban per capita GDP on house price is $6.35 \%$ and significant; the one of real estate investment is $1.37 \%$ and significant. The key reason which resulted the difference is that impact of per capita GDP and real estate investment on house price is the function of temporal series (they are collinear), and impact of urban population density on house price is only a simple factor of interior demand. Since Chinese urbanization process is accelerating, real estate $t$ market has been the one demand exceeds supply. It indicates that real estate size and population requirement has not formed stable linear relation.

Column 5 was made based on the result of column 4, in which variable of urban population density of built-up zone was excluded because it had less significant impact on house price as above. Column 6 was made based on the result of column 5, in which variable of the fourth preparing year was added because it had significant impact on house price as above. The results of regressions both coincide with the previous ones.

Owing to both regression results by OLS and fixed-effect panel model being consistent, Hausman tests would not be examined any more.

\section{Further Illustration}

There are two factors promoting development of real estate in China. One is rapid economic growth and urbanization in China. Another one is expectation about house price of inhabitants. Nowadays, a number of commodity houses in China were bought by investing in order to get added value when the price will rise in the future. Therefore, real estate price in the market has close relations with price-rising expectation of inhabitants. In order to provide more proofs for above results, surveying data of urban residents and macroeconomic cycle analysis will be illustrated respectively.

\subsection{Illustration of Surveying Residents' Data}

In order to get more information from inhabitants, field survey was carried on in April 2007 with 2,040 families being involved around twelve districts in Beijing by taking questionnaire room by room. The survey showed that $21.8 \%$ of residents thought that house price could continue to rise after Olympic Games, 25.4\% to impartial, 44.7\% to drop respectively. At the same time, about the plan to buy house, $73 \%$ of residents answered that Olympic Games had not impact on their purchasing-house decision, $14.9 \%$ postponing buying house and, $2.6 \%$ purchasing in advance.

\section{$<$ Table 3 about here $>$}

As a result, even though nearly half of residents thought that house price had been affected by staging Olympic Games, more than $70 \%$ of residents did not think that the Games affected their decision about guying house. It is that this decision determined house price. All those results indicated that residents had certainly not attached importance to Olympic impact on real estate price.

\subsection{Illustration of Macroeconomic Cycle}

No doubt, real estate price rising has correlation with macroeconomic cycle. In order to describe the relationship between real estate price and Beijing's economical cycle, the coordinative effect analysis about real estate price cycle and economic cycle will be denoted with annual data for ten years.

\subsubsection{Methdology and Data}

"Gap" between GDP and average selling price of commercial house in Beijing will be taken as indicators characterizing economical cycle and real estate price cycle respectively. Then consistence between them will be discovered by comparing their changing trends. Here, "gap" refers to the ratio between periodical fluctuation ingredient and long-term trend ingredient. The periodical fluctuation ingredient excluded long-term trend ingredient. The ratio can reflect both real proportion of fluctuation with trend ingredient and fluctuation range of real estate price after trend ingredient is eliminated. Comparing with the growth rate or composite index, "the gap" can characterize periodical fluctuation more comprehensively and accurately.Calculating Process is as the followings.

Firstly, in order to minimize loss function, actual variable value will be decomposed into tendency ingredient and cyclical ingredient by HP filtering approach. The formula is as the followings:

$\sum_{t=1}^{t}\left(\mathrm{Y}_{\mathrm{t}}-\mathrm{Y}^{*}\right)^{2}+\lambda \sum_{t=2}^{t-1}\left[\left(Y_{t+1} *-Y_{t}^{*}\right)-\left(Y_{t}^{*}-Y_{t-1} *\right]^{2}\right.$

When GDP, GDP*(gap of GDP) and RP (real estate price), RP* (gap of real estate price) takes place Y and Y* respectively as real outputs and tendency outputs. In order to take annual data, $\lambda=100$ has to be supposed.

Secondly, "gaps" of GDP and real estate price can be calculated separately. The formula is the followings:

$\mathrm{GGDP}=\frac{\mathrm{GDP}-\mathrm{GDP} *}{G D P^{*}} \quad G R P=\frac{R P-R P^{*}}{R P^{*}}$ 
Positive "gap" value means that actual value is higher than tendency value with rising period, rising scope of indicator value is faster than the one of tendency value. Negative "gap" value indicates that actual value is lower than tendency value, rising scope of indicator value is slower than the one of tendency value. When "gap" value is zero, value of this indicator is the same as long-term tendency value.

Data is denoted from1996-2006. Value of GDP is adjusted by GDP implicit index according to annual GDP index from "Statistic Yearbook of Beijing 2007". House price index is adjusted from 1996 by CPI.

\subsubsection{Results}

"Gap" value and the actual value is shown in Table 4.

$<$ Table 4 about here $>$

According to values in Table 4, Periodical fluctuation is showed in Figure 1.

$<$ Figure 1 about here $>$

Results from above values show that there has been periodical fluctuation of GDP gap and real estate price gap in Beijing in the past ten years. Moreover, two cycles last probably 10 years and there has been half of the cycle difference between them. In 1997-2006, price gap of real estate happen to be an intact cycle, but macroeconomic gap began actually rising period of a cycle (since 1997), will transfer to another cycle after ten years (since 2007). Period of rising gap needs 1-2 years and the one of falling needs 7-8 years or so. Then it can be inferred that falling tendency of macroeconomic gap might continue to 2010, and then will transfer to rising tendency. At the same time, gap of real estate price has started to be falling period since 2007. As real estate price at present is far away from the tendency value and will have a long way off the actual price during falling period of "the gap". Therefore, from the point of macroeconomic view, rising tendency of real estate price will gradually become tabular, the actual price would not be able to drop in the near future.

\section{Conclusion}

Taking into account Olympic factor and the macroeconomic cycle together, post-Olympic economy of staging cities, as a rule, is going to be on the wane for 2-3 years, after that, will continue growing for about 15 years resulting from many long-term and potential advantages in post-Olympic period. Therefore, pre-Olympic short-term factors can make real estate price gap to accelerate declining in 2008-2010. However, present price of real estate is far away from long-term tendency value, falling of "gap" for 2-3 years could not make both the gap zero and real estate price drop. According to duration of above cycle, it is that real estate gap value would close zero, economic cycle will be rise period in next cycle after 2015. What's more, economy in Bohai Rim Area (Beijing is the center of this area) will be the next growth pole after pearl river Yangtse river areas, real estate will quickly pass negative gap and come to next rising period, which would become dynamics for real estate price in Beijing. As a result, Olympic impact on real estate price happens to the influence of macroeconomic cycle with only an obvious catalysis to the growth tendency and gap amplitude of the price, but without changing basic situation.

Rapid growth of Chinese economy has been sustaining preparing and staging Olympic Games. Therefore, preparing and staging Olympic Games is both outcome and roll booster of national economic development. Hence, Olympic impact on economy has been attaching momentous importance to macroeconomic situation. As host city, Olympic impact on real estate represents character of well-marked industries, as well as other industries. Hereby, staging Olympic Games had been magnifying rising trend of real estate price before 2008, it might continue to magnify the wane trend in the next 3-5 years after 2008. However, general trend of real estate price will be consistent with economic cycle in Beijing.

\section{References}

Hechman, etc. (1996). Commends in tax policy and the economy, Cambridge, MA: MIT Press, pp32-8.

Hodrick, R. J. \& Prescott, (1980). Post war U.S. business cycle: an empirical investigation, working paper of Carnegie University.

Hotchkiss, etc. (2003). Impact of the 1996 Summer Olympic games on employment and wages in Georgia, Southern Economic Journa, 69 (3), pp691-704.

Kuo, Q. \& Jia, J. (2005). The assessment of the total factors productivity in China: 1979-2004. Economic research, pp.51-60. 
Table 1. Optimal least squares regression of Olympic impacts

\begin{tabular}{|c|c|c|c|c|c|}
\hline \multirow{2}{*}{ independent variables } & \multicolumn{5}{|c|}{ Coefficients of dependent variable } \\
\hline & 1 & 2 & 3 & 4 & 5 \\
\hline \multirow{2}{*}{ intercept } & $1.680357 * * *$ & $1.604167 * * *$ & $1.680357 * * *$ & $1.604167 * * *$ & 5.781163 \\
\hline & -3.33 & -3.61 & -3.4 & -3.7 & -0.82 \\
\hline \multirow{2}{*}{ Host (assisting)cities } & -0.3428571 & & -0.597024 & & -0.390771 \\
\hline & $(-0.32)$ & & $(-0.51)$ & & $(-0.36)$ \\
\hline \multirow{2}{*}{ period of preparing } & $3.742857 * * *$ & $4.118056^{* * *}$ & $3.742857 * * *$ & $3.825245 * * *$ & $3.884482 * * *$ \\
\hline & -5.25 & -6.56 & -5.36 & -6.14 & -4.81 \\
\hline \multirow{2}{*}{ Olympic impact } & 1.688393 & & & & 1.725316 \\
\hline & -1.12 & & & & -1.13 \\
\hline \multirow{2}{*}{ first year of preparing (2001) } & & & 1.016667 & & \\
\hline & & & -0.48 & & \\
\hline \multirow{2}{*}{ second year of preparing (2002) } & & & -1.82619 & & \\
\hline & & & $(-0.81)$ & & \\
\hline \multirow{2}{*}{ third year of preparing (2003) } & & & 0.6988096 & & \\
\hline & & & -0.31 & & \\
\hline \multirow{2}{*}{ fourth year of preparing (2004) } & & & $5.87381 * * *$ & $5.270588 * * *$ & \\
\hline & & & -2.61 & -2.78 & \\
\hline \multirow{2}{*}{ fifth year of preparing (2005) } & & & 3.023809 & & \\
\hline & & & -1.35 & & \\
\hline \multirow{2}{*}{ per capita GDP } & & & & & 0.2993522 \\
\hline & & & & & -0.37 \\
\hline \multirow{2}{*}{$\begin{array}{c}\text { Urban population density } \\
\text { of built-up zone }\end{array}$} & & & & & -0.738555 \\
\hline & & & & & $(-0.99)$ \\
\hline \multirow{2}{*}{ real estate investment } & & & & & -0.136686 \\
\hline & & & & & $(-0.32)$ \\
\hline number of the sample & 144 & 144 & 144 & 144 & 144 \\
\hline $\mathrm{R}^{2}$ & 0.2415 & 0.2324 & 0.292 & 0.2723 & 0.2479 \\
\hline
\end{tabular}

Note: * Significant at 90\% confidence level; ** Significant at 95\% confidence level; $* * *$ Significant at $99 \%$ confidence level.(the same as next table) 
Table 2. Fixed-effect panel model (differences-in-differences regressions)

\begin{tabular}{|c|c|c|c|c|c|c|}
\hline \multirow{2}{*}{ independent variables } & \multicolumn{6}{|c|}{ Coefficients of the dependent variable } \\
\hline & 1 & 2 & 3 & 4 & 5 & 6 \\
\hline \multirow{2}{*}{ intercept } & $1.604167 * * *$ & $1.547685^{* * *}$ & $1.604167 * * *$ & $-71.3149 * * *$ & $-71.0518 * * *$ & $-72.38166^{* * *}$ \\
\hline & -4.24 & -4.1 & -4.42 & $(-3.15)$ & $(-4.5)$ & $(-5.03)$ \\
\hline \multirow{2}{*}{$\begin{array}{l}\text { period of } \\
\text { preparing }\end{array}$} & $3.742857 * * *$ & $3.742857 * * *$ & $3.612 * * *$ & 0.1489381 & & \\
\hline & -6.17 & -6.41 & -6.78 & -0.15 & & \\
\hline \multirow{2}{*}{ Olympic impact } & 1.688393 & & & 1.508797 & 1.612443 & \\
\hline & -1.31 & & & -1.24 & -1.38 & \\
\hline \multirow{2}{*}{$\begin{array}{c}\text { first year } \\
\text { of preparing (2001) }\end{array}$} & & 1.016667 & & & & \\
\hline & & -0.57 & & & & \\
\hline \multirow{2}{*}{$\begin{array}{c}\text { second year } \\
\text { of preparing (2002) }\end{array}$} & & -1.82619 & & & & \\
\hline & & $(-0.97)$ & & & & \\
\hline \multirow{2}{*}{$\begin{array}{c}\text { third year } \\
\text { of preparing (2003) }\end{array}$} & & 0.6988096 & & & & \\
\hline & & -0.37 & & & & \\
\hline \multirow{2}{*}{$\begin{array}{c}\text { fourth year } \\
\text { of preparing (2004) }\end{array}$} & & $5.87381 * * *$ & $5.9795 * * *$ & & & $4.814656^{* * *}$ \\
\hline & & -3.13 & -3.52 & & & -3.05 \\
\hline \multirow{2}{*}{$\begin{array}{c}\text { fifth year } \\
\text { of preparing (2005) }\end{array}$} & & 3.023809 & $3.1295 * *$ & & & \\
\hline & & -1.61 & -1.84 & & & \\
\hline \multirow{2}{*}{ per capita GDP } & & & & $6.350909 * * *$ & $6.866137 * * *$ & $7.031125 * * *$ \\
\hline & & & & -2.68 & -3.76 & -4.19 \\
\hline \multirow{2}{*}{$\begin{array}{l}\text { Urban population } \\
\text { density of } \\
\text { the built-up zone }\end{array}$} & & & & 0.6050512 & & \\
\hline & & & & -0.42 & & \\
\hline \multirow{2}{*}{$\begin{array}{l}\text { The investment } \\
\text { of real estate }\end{array}$} & & & & $1.369027^{* *}$ & $1.3689 * *$ & $1.315991 * *$ \\
\hline & & & & -2 & -2.07 & -2.05 \\
\hline $\begin{array}{l}\text { the number } \\
\text { of the sample }\end{array}$ & 144 & 144 & 144 & 144 & 144 & 144 \\
\hline $\mathrm{R}^{2}$ & 0.2404 & 0.2887 & 0.2811 & 0.0495 & 0.0693 & 0.0569 \\
\hline F statistics & $30.46^{* * *}$ & $13.28 * * *$ & $26.12 * * *$ & $18.33 * * *$ & $30.92 * * *$ & $35.2^{* * *}$ \\
\hline
\end{tabular}


Table 3. Surveying data of 2,040 residents in 12 Beijing's districts

\begin{tabular}{|c|c|c|c|c|c|}
\hline & $\begin{array}{c}\text { sample } \\
\text { number } \\
\text { (person) }\end{array}$ & $\begin{array}{c}\text { percent of } \\
\text { total samples(\%) }\end{array}$ & $\begin{array}{c}\text { sample number } \\
\text { (person) }\end{array}$ & $\begin{array}{c}\text { percent } \\
\text { of } \\
\text { total samples(\%) }\end{array}$ \\
\hline ascend & 444 & 21.8 & no impact & 1491 & 73.1 \\
\hline descend & 911 & 44.7 & postponing buying & 303 & 14.9 \\
\hline impartial & 518 & 25.4 & in advance & 54 & 2.6 \\
\hline not clear & 167 & 8.2 & abandon buying & 192 & 9.4 \\
\hline total & 2040 & 100 & total & 2040 & 100 \\
\hline
\end{tabular}

Table 4. Beijing's changing gap of GDP and real estate price in 1996-2005

\begin{tabular}{|c|c|c|c|c|c|c|c|c|c|c|}
\hline & 1996 & 1997 & 1998 & 1999 & 2000 & 2001 & 2002 & 2003 & 2004 & 2005 \\
\hline GGDP & 0.059 & 0.014 & -0.038 & -0.116 & -0.150 & 0.067 & 0.049 & 0.032 & 0.031 & -0.007 \\
\hline GRP & 0.0 .25 & 0.249 & 0.072 & 0.041 & -0.056 & -0.067 & -0.115 & -0.136 & -0.110 & 0.224 \\
\hline
\end{tabular}

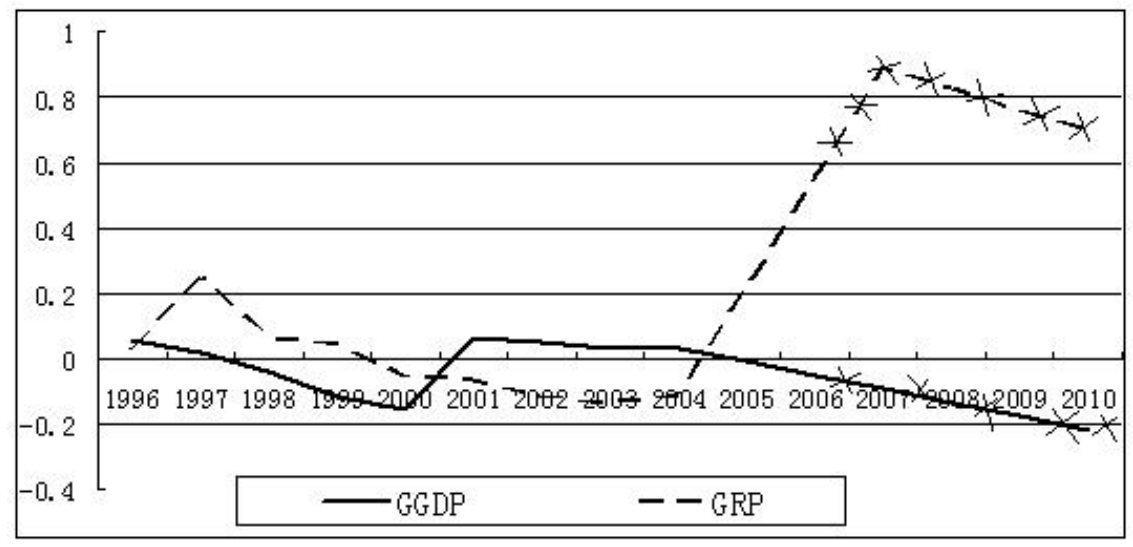

Figure 1. Periodical fluctuation of GDP and real estate price in Beijing Note: Curve with * is forecast line according to preceding period 